BMJ Open

Ophthalmology

\title{
Five-year follow-up outcomes after Descemet's stripping automated endothelial keratoplasty: a retrospective study
}

Koichi Wakimasu, ${ }^{1}$ Koji Kitazawa (D) , ${ }^{1,2}$ Kanae Kayukawa, ${ }^{1}$ Isao Yokota, ${ }^{3}$ Tsutomu Inatomi, ${ }^{2}$ Osamu Hieda, ${ }^{2}$ Chie Sotozono, ${ }^{2}$ Shigeru Kinoshita ${ }^{1,4}$

To cite: Wakimasu $\mathrm{K}$, Kitazawa K, Kayukawa K, et al. Five-year follow-up outcomes after Descemet's stripping automated endothelial keratoplasty: a retrospective study. BMJ Open Ophthalmology 2020;5:e000354. doi:10.1136/ bmjophth-2019-000354

- Additional material is published online only. To view please visit the journal online (http://dx.doi.org/10.1136/ bmjophth-2019-000354).

$\mathrm{KW}$ and KK contributed equally.

Received 6 June 2019 Revised 10 October 2019 Accepted 11 November 2019

Check for updates

(C) Author(s) (or their employer(s)) 2020. Re-use permitted under CC BY-NC. No commercial re-use. See rights and permissions. Published by BMJ.

${ }^{1}$ Ophthalmology, Baptist Eye Institute, Kyoto, Japan ${ }^{2}$ Ophthalmology, Kyoto prefectural univeristy of medicine, Kyoto, Japan ${ }^{3}$ Biostatistics, Kyoto prefectural university of medicine, Kyoto, Japan

${ }^{4}$ Frontier Medical Science and Technology for Ophthalmology, Kyoto prefectural university of medicine, Kyoto, Japan

Correspondence to Dr Shigeru Kinoshita; shigeruk@ koto.kpu-m.ac.jp

\section{ABSTRACT}

Objective To assess graft survival and endothelial cell density (ECD) over a 5-year follow-up period after Descemet's stripping automated endothelial keratoplasty (DSAEK).

Methods and analysis This retrospective study involved 130 eyes of 130 consecutive patients with Fuchs endothelial corneal dystrophy (FECD), non-FECD bullous keratopathy (BK) (non-FECD) or BK post-trabeculectomy or tube-shunt surgery (glaucoma with bleb) who underwent DSAEK between August 2007 and January 2012 and were followed for more than 5 years postoperatively. Patients with previous keratoplasty, graft suture failure, primary graft failure, postoperative endophthalmitis and ocular infection were excluded. Graft survival and ECD was then examined in all patients who underwent DSAEK and completed the postoperative follow-up period. The association between clinical factors and 5-year graft survival after DSAEK was analysed with multivariate logistic regression analysis.

Results The overall graft survival rate at 5 years postoperatively was $85 \%$, yet significantly poorer in the glaucoma with bleb eyes (47\%) than in the FECD $(100 \%)$ or non-FECD (90\%) eyes ( $p<0.01$, log-rank test). In the FECD, non-FECD and glaucoma with bleb eyes, the mean ECD at 5 years postoperatively was 1054 cells/ $\mathrm{mm}^{2}, 1137$ cells/ $\mathrm{mm}^{2}$ and $756 \mathrm{cells} / \mathrm{mm}^{2}$, respectively. Multivariate logistic regression analysis showed history of trabeculectomy or tube-shunt surgery and postoperative allograft rejection to be negative factors for graft survival at 5 years after DSAEK (OR $0.01,95 \% \mathrm{Cl} 0.00$ to 0.10 and $0 \mathrm{R} 0.02,95 \% \mathrm{Cl} 0.00$ to 0.33 , respectively).

Conclusion Our findings show that at 5 years postoperatively, the surgical outcome after DSAEK was poorer in eyes after trabeculectomy or tube-shunt surgery. Trial registration number UMIN000024891.

\section{INTRODUCTION}

Endothelial keratoplasty (EK) is a well-known surgical procedure for the treatment of bullous keratopathy (BK), a pathological condition caused by corneal endothelial dysfunction. ${ }^{1-7}$ It has been reported that in terms of better visual function, less astigmatism and a lower rate of graft rejection and wound dehiscence

\section{Key messages}

\section{What is already known about this subject? \\ Descemet's stripping automated endothelial kerato- plasty (DSAEK) is a well-known surgical procedure for the treatment of bullous keratopathy (BK). To date, there have been no published reports involving over 130 patients with BK due to a variety of causes who were followed up for over 5 years after DSAEK.}

\section{What are the new findings?}

$>$ Our findings revealed that the overall graft survival rate at 5 years after DSAEK was $85 \%$, yet significantly poorer in the glaucoma with bleb eyes (47\%), and multivariate analysis revealed that a history of trabeculectomy or tube-shunt surgery and postoperative allograft rejection were high-risk factors for graft failure at 5 years after DSAEK.

\section{How might these results change the focus of research or clinical practice? \\ - Further study is needed to elucidate the optimal clinical management and additional treatments re- quired after DSAEK in patients with BK with a history of glaucoma surgery.}

after surgery, ${ }^{6} 7 \mathrm{EK}$ is a procedure that is superior to penetrating keratoplasty (PK). More than a decade has now passed since Descemet's stripping endothelial keratoplasty and Descemet's stripping automated endothelial keratoplasty (DSAEK), respectively, were first reported by Price and Price $^{3}$ in 2005 and Govoroy, ${ }^{5}$ Melles ${ }^{8}$ and Terry et at in 2006. It was recently reported that in comparison to $\mathrm{EK}$, the number of cases undergoing Descemet's membrane endothelial keratoplasty (DMEK) is on the increase. ${ }^{10}$ However, in 2017, over 20000 eyes in the USA underwent DSAEK, while only 7000 eyes underwent DMEK, thus illustrating that DSAEK remains the primary surgical option for the treatment of BK.

In order to properly assess the safety and efficacy of DSAEK, it is necessary to evaluate 
the long-term postoperative results, and previous studies have compared the clinical outcomes between DSAEK and PK. Price et al reported that the 5-year donor graft survival and corneal endothelial cell density (ECD) after DSAEK is superior to that after PK, ${ }^{11}$ however, by 10 years postoperatively, the amount of endothelial cell loss after DSAEK and after PK was comparable. ${ }^{12}$ Moreover, in a cohort study involving Asian eyes, Ang et al reported similar results using a standardised surgical procedure and postoperative follow-up course. ${ }^{13}$ It should be noted that the majority of the previous reports on DSAEK involved patients afflicted with Fuchs endothelial corneal dystrophy (FECD). However, a study from a tertiary referral hospital in Japan reported that the trend of DSAEK for the treatment of BK due to FECD has decreased, yet has increased for the treatment of BK following trabeculectomy. ${ }^{14}$

The purpose of this present study was to investigate the clinical outcomes in consecutive BK cases over a 5-year follow-up period after DSAEK, including the rate of donor graft survival and ECD.

\section{MATERIALS AND METHODS}

Study design and patients

This retrospective cohort study of ECD after DSAEK was registered at the University Hospital Medical Information Network (UMIN) (http://www.umin.ac.jp/english/). In accordance with the tenets set forth in the Declaration of Helsinki, written informed consent was obtained from all patients prior to their involvement in the study.

This study involved 239 consecutive patients who underwent DSAEK surgery by corneal experts at the Baptist Eye Institute, Kyoto, Japan, between August 2007 and January 2012. Of those 239 cases, 42 were excluded due to it being the data of the contralateral eye of the same patient ( $\mathrm{n}=8$ cases) and a history that could lead to an acceleration of ECD loss, such as previously undergoing keratoplasty ( $n=23$ cases), graft suture ( $n=4$ cases), primary graft failure ( $\mathrm{n}=3$ cases), postoperative endophthalmitis ( $\mathrm{n}=1$ case) and ocular infection ( $\mathrm{n}=3$ cases). Of those remaining 197 cases, $130(66.0 \%)$ were followed for more than 5 years postoperatively and investigated.

The mean age of the 130 patients included in this study was $70.8 \pm 10.1$ years (mean $\pm \mathrm{SD}$; range $34-86$ years), and the patients were classified into the following three primary groups: (1) cases with BK due to FECD ( $n=17$ cases); (2) cases without FECD (ie, non-FECD), including laser iridotomy-induced BK (LI-BK) ( $\mathrm{n}=47$ cases), pseudophakic BK or aphakic BK (PBK/ABK) ( $\mathrm{n}=24$ cases), corneal endotheliitis ( $\mathrm{n}=7$ cases), pseudoexfoliation (PEX) keratopathy ( $\mathrm{n}=3$ cases), iridocorneal endothelial syndrome ( $\mathrm{n}=3$ cases), trauma-induced $\mathrm{BK}$ ( $\mathrm{n}=3$ cases), BK after Sato-type anterior-posterior corneal refractive surgery ( $n=2$ cases) and BK due to unknown causes $(n=5$ cases); and (3) cases had previously undergone trabeculectomy alone ( $\mathrm{n}=18$ cases), and both trabeculectomy and tube-shunt surgery ( $\mathrm{n}=1$ case) (glaucoma with bleb) $(n=19$ cases $)$. Of the 130 included cases, DSAEK was performed in combination with lens surgery in 54 (ie, 8 FECD cases, 44 non-FECD cases and 2 glaucoma with bleb cases).

\section{Surgical technique}

All donor corneas were obtained from SightLife Eye Bank (Seattle, Washington), and all DSAEK flaps used for implantation were prepared by SightLife prior to being shipped to Japan. The techniques used for all DSAEK surgeries were as previously described ${ }^{15}$ Briefly, after an anterior chamber maintainer was set up, the Descemet's membrane at the central posterior cornea was removed using a reverse Sinskey hook (Bausch \& Lomb, Rochester, New York). A corneal graft button approximately $8.0 \mathrm{~mm}$ in diameter, yet appropriately adjusted to match the diameter of the host cornea, was then cut for transplantation by use of a Barron Vacuum Punch (Barron Precision Instruments, Grand Blanc, Michigan). Using a Busin glide, the prepared DSAEK flap was then inserted into the anterior chamber through a $4 \mathrm{~mm}$ incision at the temporal region of the corneal limbus. The inserted flap was then positioned stromal side up, and air was injected into the anterior chamber in order to sufficiently increase the intraocular pressure (IOP) to firmly attach the graft to the host cornea. After $10 \mathrm{~min}$, the IOP was adjusted to over $10-20 \mathrm{~mm} \mathrm{Hg}$ by adding and aspirating air and BSS PLUS Irrigating Solution (Alcon, Geneva, Switzerland) using a 30 or $32 \mathrm{G}$ needle. In the patients who underwent combined cataract surgery, a separate $2.5 \mathrm{~mm}$ wide scleral tunnel was made at the superior position for phacoemulsification and aspiration, followed by intraocular lens (IOL) implantation via the use of an IOL insertion device (Alcon) prior to the DSAEK procedure being performed.

\section{Postoperative management}

As per the protocol reported in our previous study, ${ }^{16}$ following DSAEK, each patient received a systemic dose of $125 \mathrm{mg}$ methylprednisolone 1 hour prior to surgery, and then a systemic dose of $4 \mathrm{mg}$ betamethasone for 2 days postoperatively followed by $1 \mathrm{mg}$ betamethasone for an additional 5 days. In addition, a topical application of $0.3 \%$ gatifloxacin and $0.1 \%$ betamethasone eye drops was administered four times daily, and at 6 months after DSAEK, the $0.1 \%$ betamethasone eye drops were switched to $0.1 \%$ fluorometholone eye drops instilled two to four times daily. For the patients with general problems, such as poor control of diabetes or renal failure, and so on, the systemic dose of steroid was appropriately adjusted. In all patients, the use of antiglaucoma eye drops was discontinued at the time of surgery.

\section{Clinical examination}

In each patient, the preoperative ECD of the donor graft was obtained from the donor information provided by SightLife Eye Bank, and at every 6 months postoperatively, ECD was measured by use of a non-contact specular microscope (EM-2000 or EM-3000; TOMEY, Nagoya, Japan). Corneal graft failure was defined as irreversible 
corneal oedema. Cases with graft failure, and cases with a clear graft in which clear specular microscopy images could not be obtained, were excluded from the postoperative ECD analysis. The donor graft survival rate was recorded every 6 months postoperatively, and was defined as the percentage of clear grafts.

\section{Statistical analysis}

Statistical analyses were performed using JMP Pro V.12.1.0 statistical analysis software (SAS, Cary, North Carolina). The cumulative donor graft survival rate was analysed by the Kaplan-Meier method and log-rank test. In order to elucidate if there was any bias due to the high dropout rate in the included patients $(\mathrm{n}=130,66.0 \%)$ who were followed for more than 5 years postoperatively, we reanalysed the rate of graft survival after DSAEK in the patients who were followed for 2 years postoperatively $(n=170$, $86.3 \%)$ and for 3 years postoperatively $(n=149,75.6 \%)$.

To identify causative clinical factors associated with 5-year graft survival of post-DSAEK, the analysis was performed with multivariate logistic regression analysis adjusted for donor ECD that included patient age at surgery, patient gender, donor age, donor graft size, donor gender, the presence of combination with cataract surgery, anterior iris synechia, sutured IOL, bleb, air removal due to pupillary block, air rebubbling, postoperative rejection and additional postoperative glaucoma surgery as covariates. The incidence OR with 95\% CIs was calculated. A p value of less than 0.05 was considered statistically significant.

\section{RESULTS}

Of the 197 cases who were followed for more than 5 years after DSAEK, donor graft survival rate and postoperative ECD was examined in 130 eyes of 130 patients. The overall donor graft survival rate at 1, 2, 3, 4 and 5 years postoperatively was $99 \%, 95 \%, 93 \%, 87 \%$ and $85 \%$, respectively (figure 1A). The 5-year cumulative graft survival rate in the FECD cases $(n=17)$ was relatively comparable to that
A

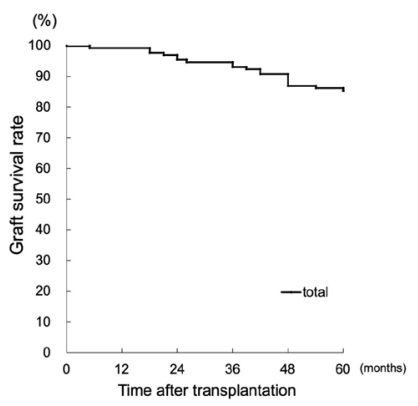

B

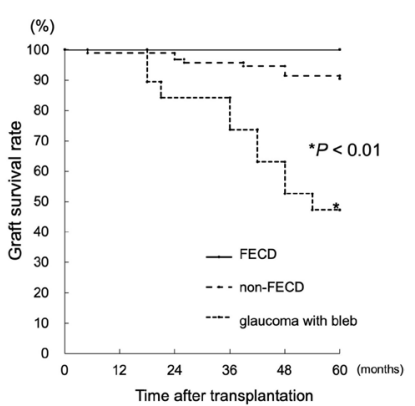

Figure 1 Graphs showing a cumulative Kaplan-Meier graft survival curve after Descemet's stripping endothelial keratoplasty (DSEK) in total eyes (A) and in three different groups, including Fuchs endothelial corneal dystrophy (FECD), non-FECD bullous keratopathy (BK) (ie, non-FECD) and patients with BK with a history of trabeculectomy or tube-shunt surgery (glaucoma with bleb) (B). Asterisk indicates a $p$ value less than 0.01 (log-rank test). in the non-FECD cases $(n=94)$ (ie, $100 \%$ in the FECD cases and $90 \%$ in the non-FECD cases, $\mathrm{p}=0.18$ ). However, in the glaucoma with bleb cases $(n=19)$, the 5 -year cumulative graft survival rate from the second year to 5 years postoperatively was consistently poorer than that in the FECD and non-FECD cases $(p<0.01)$, and the donor graft survival rate at 1, 2, 3, 4 and 5 years postoperatively was $100 \%, 84 \%, 74 \%, 53 \%$ and $47 \%$, respectively (figure $1 \mathrm{~B}$ ), in the glaucoma with bleb cases.

In order to investigate whether there was any bias due to the high dropout rate in this study, we reanalysed the rate of donor graft survival in the patients who were followed for 2years postoperatively $(n=170)$ and for 3 years postoperatively $(n=149)$. The overall donor graft survival rate at 2 years postoperatively was $97 \%$ in the 2-year follow-up group and $96 \%$ in the 3-year follow-up group, respectively, while that at 3 years postoperatively was $94 \%$ in the 3-year follow-up group. The donor graft survival rate in the glaucoma with bleb cases at 2 years postoperatively was $89 \%$ in the 2-year follow-up group $(n=28)$ and $87 \%$ in the 3-year follow-up group $(n=23)$, respectively, while that at 3 years postoperatively was $78 \%$ in the 3-year follow-up group $(n=23)$. Moreover, the donor graft survival rate over 2 years postoperatively in the glaucoma and bleb subgroup was poorer than that in the FECD and non-FECD cases (online supplementary figures 1 and 2).

The average ECD (mean \pm SD) after DSAEK was assessed during the 5-year follow-up period and at 1 , 2, 3, 4 and 5 years postoperatively was $1925 \pm 514$ cells/ $\mathrm{mm}^{2}, \quad 1719 \pm 585$ cells $/ \mathrm{mm}^{2}, \quad 1467 \pm 617$ cells $/ \mathrm{mm}^{2}$, $1244 \pm 609$ cells $/ \mathrm{mm}^{2}$ and $1096 \pm 604$ cells $/ \mathrm{mm}^{2}$, respectively (table 1). Postoperative ECD analyses among the three groups (ie, the included FECD cases, non-FECD cases and glaucoma with bleb cases) revealed that the ECD of the FECD cases was comparable to that of the non-FECD cases during the 5-year postoperative period, while that of the glaucoma with bleb cases was decreased compared with that of both the FECD cases and the non-FECD cases at 1 year postoperatively and was clearly declining over the 5-year postoperative period (figure 2 and table 1).

To investigate the risk factors between the clinical factors and the 5-year graft survival after DSAEK, multivariate logistic regression analysis was performed. After DSAEK, of the 130 cases included in the study, 9 cases required air removal due to pupillary block, 8 cases required air rebubbling, 7 cases exhibited allograft rejection and 8 cases required additional glaucoma surgery. Of the various clinical factors, we found that a history of trabeculectomy or tube-shunt surgery was a negative factor for graft survival at 5 years after DSAEK (OR $0.01,95 \%$ CI 0.00 to $0.10, \mathrm{p}<0.01$ ), that postoperative allograft rejection was a high-risk factor for graft failure (OR $0.02,95 \%$ CI 0.00 to $0.33, \mathrm{p}<0.01)$ and that there was no significant association between the other factors and graft survival over the 5-year postoperative period (table 2). 
Table 1 Endothelial cell density after Descemet's stripping automated endothelial keratoplasty (DSAEK)

\begin{tabular}{|c|c|c|c|c|}
\hline \multirow{2}{*}{$\begin{array}{l}\text { The causes of bullous } \\
\text { keratopathy }\end{array}$} & \multicolumn{4}{|c|}{ Endothelial cell density (cells $/ \mathrm{mm}^{2}$ ) } \\
\hline & Baseline & 1 year & 3years & 5 years \\
\hline \multirow[t]{2}{*}{ FECD } & $\begin{array}{l}2868 \\
(2504-3325)\end{array}$ & $\begin{array}{l}2044 \\
(1303-2434)\end{array}$ & $\begin{array}{l}1595 \\
(655-2349)\end{array}$ & $\begin{array}{l}1054 \\
(504-2303)\end{array}$ \\
\hline & $(n=17)$ & $(n=17)$ & $(n=16)$ & $(n=16)$ \\
\hline \multirow[t]{2}{*}{ Non-FECD } & $\begin{array}{l}2937 \\
(2306-3673)\end{array}$ & $\begin{array}{l}1943 \\
(500-2938)\end{array}$ & $\begin{array}{l}1469 \\
(454-2627)\end{array}$ & $\begin{array}{l}1137 \\
(348-2517)\end{array}$ \\
\hline & $(n=94)$ & $(n=93)$ & $(n=86)$ & $(n=82)$ \\
\hline \multirow[t]{2}{*}{ Glaucoma with bleb } & $\begin{array}{l}2978 \\
(2519-3642)\end{array}$ & $\begin{array}{l}1731 \\
(800-2569)\end{array}$ & $\begin{array}{l}1292 \\
(529-2054)\end{array}$ & $\begin{array}{l}756 \\
(500-1082)\end{array}$ \\
\hline & $(n=19)$ & $(n=19)$ & $(n=13)$ & $(n=8)$ \\
\hline \multirow[t]{2}{*}{ Total } & $\begin{array}{l}2934 \\
(2306-3673)\end{array}$ & $\begin{array}{l}1925 \\
(500-2938)\end{array}$ & $\begin{array}{l}1467 \\
(454-2627)\end{array}$ & $\begin{array}{l}1096 \\
(348-2517)\end{array}$ \\
\hline & $(n=130)$ & $(n=129)$ & $(n=115)$ & $(n=106)$ \\
\hline
\end{tabular}

Fuchs endothelial corneal dystrophy (FECD); non-FECD, laser iridotomy-induced bullous keratopathy (LI-BK), pseudophakic BK (PBK), aphakic BK (ABK), corneal endotheliitis, pseudoexfoliation keratopathy, iridocorneal endothelial syndrome, trauma-induced BK, BK after Sato-type anterior-posterior corneal refractive surgery and BK due to unknown causes; glaucoma with bleb, bullous keratopathy with history of trabeculectomy or tube-shunt surgery

\section{DISCUSSION}

In this retrospective study, we investigated the graft survival outcomes and ECD changes after DSAEK in consecutive patients with FECD, non-FECD and patients with glaucoma with bleb who underwent a minimum 5-year postoperative follow-up. As mentioned above, most previous studies on the surgical outcomes after DSAEK have primarily focused on the analysis of patients with FECD. However, in those studies, there were a variety of causes of BK that required DSAEK, such as PBK, ABK, trabeculectomy-induced BK, LI-BK, cytomegalovirusinduced BK, PEX keratopathy and trauma. Hence, the

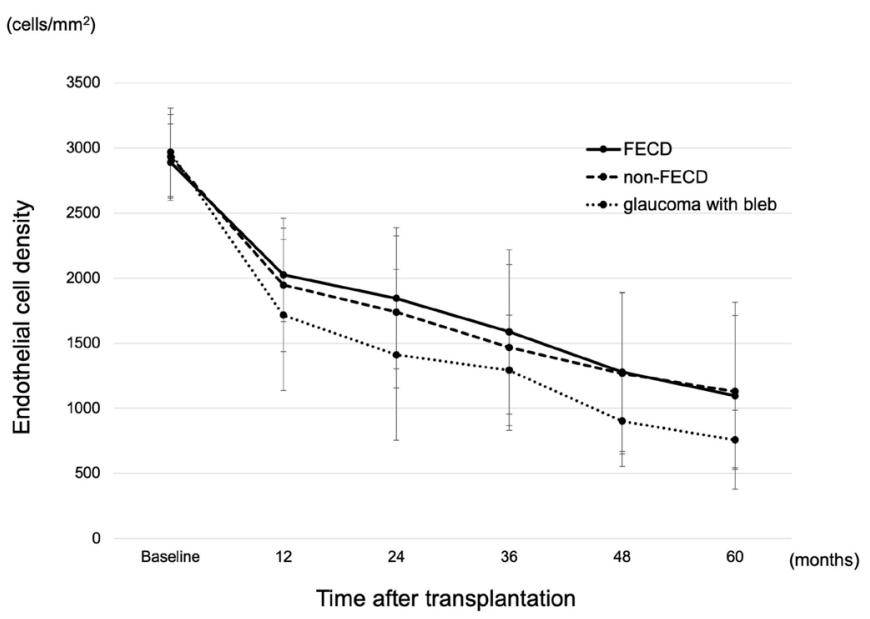

Figure 2 Graph showing a comparison of the average endothelial cell density after Descemet's stripping automated endothelial keratoplasty (DSAEK) between patients with Fuchs endothelial corneal dystrophy (FECD), non-FECD bullous keratopathy (BK) (ie, non-FECD) and BK with a history of trabeculectomy or tube-shunt surgery (glaucoma with bleb). SD is indicated by the lines above the upper and lower black dots. findings in this present study may help broaden our understanding of the long-term surgical outcomes after DSAEK.

In regard to the rate of donor graft survival after DSAEK, the 5-year cumulative graft survival rate in the glaucoma with bleb eyes was only $47.4 \%$, yet was $100 \%$ in the FECD eyes and $90.2 \%$ in the non-FECD eyes. In this present study, the overall mean ECD at 5 years after DSAEK was 1088 cells $/ \mathrm{mm}^{2}$, lower than that at the same postoperative follow-up time point reported in the previous studies (ie, 1510 cells $/ \mathrm{mm}^{2}{ }^{17} 1312$ cells $/ \mathrm{mm}^{2}{ }^{18}$ and 1322 cells/ $\left.\mathrm{mm}^{219}\right)$. However, that is probably due to the fact that the present study included cases with a history of undergoing trabeculectomy and tube-shunt surgery, which are both more likely to reduce ECD after DSAEK.

It has been reported that a previous trabeculectomy is an independent risk factor for graft detachment and graft dislocation after DSAEK. ${ }^{20-23}$ However, in this present study, air rebubbling was found to not be associated with graft failure at 5 years postoperatively. It has also been reported that even after a successful DSAEK procedure, failure of the donor graft is more likely to occur in patients with a history of glaucoma surgery, including trabeculectomy and tube-shunt surgery, ${ }^{24}{ }^{25}$ and the multivariate logistic regression analysis in this present study revealed that a history of trabeculectomy or tubeshunt surgery was one of the negative factors for graft survival at 5 years after DSAEK (OR $0.01,95 \%$ CI 0.00 to $0.10, \mathrm{p}<0.01)$.

Of continued interest is the fact that the exact mechanism by which graft failure occurs in eyes with pre-existing glaucoma is still not completely understood. It has previously been reported that aqueous humour proteome analysis revealed higher levels of oxidative, apoptotic and inflammatory plasma proteins in eyes that 
Table 2 Multivariate ORs of clinical factors for 5-year graft survival of post-DSAEK

\begin{tabular}{|c|c|c|c|c|}
\hline \multirow[b]{2}{*}{ Clinical factors } & \multicolumn{4}{|c|}{ Multivariate analysis } \\
\hline & OR & $95 \% \mathrm{Cl}$ & $P$ value & $\mathbf{n}$ \\
\hline \multicolumn{5}{|l|}{ Age at surgery } \\
\hline$>65$ years old & 4.48 & 0.71 to 28.38 & 0.11 & 106 \\
\hline \multicolumn{5}{|l|}{ Gender } \\
\hline Female & 0.50 & 0.08 to 3.21 & 0.46 & 75 \\
\hline \multicolumn{5}{|l|}{ Donor graft size } \\
\hline$>8.0 \mathrm{~mm}$ & 2.61 & 0.32 to 20.70 & 0.37 & 19 \\
\hline \multicolumn{5}{|l|}{ Donor age } \\
\hline$>65$ years old & 3.44 & 0.73 to 16.16 & 0.12 & 69 \\
\hline \multicolumn{5}{|l|}{ Donor gender } \\
\hline Female & 0.45 & 0.09 to 2.29 & 0.34 & 61 \\
\hline \multicolumn{5}{|c|}{ Combined with lens surgery } \\
\hline Yes & 0.46 & 0.09 to 2.49 & 0.37 & 54 \\
\hline \multicolumn{5}{|c|}{ Peripheral anterior synechia } \\
\hline Yes & 0.79 & 0.11 to 5.69 & 0.82 & 16 \\
\hline \multicolumn{5}{|c|}{ Scleral-suture fixated IOL } \\
\hline Yes & 0.53 & 0.06 to 4.43 & 0.56 & 11 \\
\hline \multicolumn{5}{|c|}{ Previous trabeculectomy and tube-shunt surgery } \\
\hline Yes & 0.01 & 0.00 to 0.10 & $<0.01$ & 19 \\
\hline \multicolumn{5}{|c|}{ Air removal due to pupillary block } \\
\hline Yes & 0.14 & 0.01 to 1.75 & 0.13 & 9 \\
\hline \multicolumn{5}{|l|}{ Air rebubbling } \\
\hline Yes & 5.57 & 0.19 to 159.58 & 0.32 & 8 \\
\hline \multicolumn{5}{|c|}{ Postoperative rejection } \\
\hline Yes & 0.02 & 0.00 to 0.33 & $<0.01$ & 7 \\
\hline \multicolumn{5}{|c|}{ Additional glaucoma surgery after DSAEK } \\
\hline Yes & 0.30 & 0.03 to 2.65 & 0.28 & 8 \\
\hline
\end{tabular}

Multivariate analysis was adjusted for donor endothelial cell density.

DSAEK, Descemet's stripping automated endothelial keratoplasty;IOL, intraocular lens.

have undergone glaucoma surgery. ${ }^{26} 27$ Currently, repeat DSAEK is the only surgical procedure available for visual recovery in patients with glaucoma who experience repeat graft failure. ${ }^{28} 29$ However, although we previously reported that there were no significant differences in the surgical outcomes among the number of repeat PKs performed ${ }^{30}$ the surgical outcomes following repeat DSAEK have yet to be fully elucidated. Thus, further investigation is needed in regard to surgical outcomes and the number of repeat DSAEK performed.

It should be noted that this present study did have several limitations. The first limitation is that $34 \%$ of patients who underwent DSAEK dropped out of the study during the 5-year follow-up period, primarily because it was difficult for elderly patients and patients living in remote areas to continuously visit our institute for long-term follow-up examinations. The data reanalysed in the 2-year and 3-year follow-up groups suggest that there might be more patients who remained with poor prognosis in longer follow-up. However, we found that there was a similar trend in donor graft survival among the 2, 3 and 5-year follow-up groups, thus demonstrating that glaucoma with bleb was the subgroup with a lower donor graft survival rate compared with that of the FECD and non-FECD cases. The second limitation is over a $33 \%$ of the patients included in this study were BK secondary to laser iridotomy, which is relatively unique pathology in Asian countries. ${ }^{31}$ However, our findings did indicate that a history of trabeculectomy or tube-shunt surgery was a negative factor for donor graft survival. The third limitation is that this was a retrospective study. For example, even though we did discover that a history of glaucoma surgery could result in earlier failure of the donor graft, the number of cases in which that occurred was small. Thus, in order to confirm the reproducibility of our findings, a prospective study involving a larger cohort of patients is needed. 
In conclusion, the findings of this detailed 5-year follow-up study revealed that the graft survival rate and ECD after DSAEK was lower in eyes with a history of trabeculectomy or tube-shunt surgery.

Acknowledgements The authors thank John Bush for reviewing the manuscript. Contributors Conception and design of the study: KW, KoK, SK. Collection of data: KW, KoK, KaK, IY, TI, OH, CS, SK. Management of data: KW, KoK. Analysis of data: KW, KoK, IY. Interpretation of data: KW, KoK, IY. Writing of the article: KW, KoK, SK. Approval of the manuscript: KW, KoK, KaK, IY, TI, OH, CS, SK. Obtained funding: CS, SK. Searching the literature: KW, KoK.

Funding The authors have not declared a specific grant for this research from any funding agency in the public, commercial or not-for-profit sectors.

Competing interests None declared.

Patient consent for publication Not required.

Ethics approval Kyoto Ethics Review Board, Kyoto, Japan (approval number: 1604).

Provenance and peer review Not commissioned; externally peer reviewed.

Data availability statement All data relevant to the study are included in the article or uploaded as supplementary information.

Open access This is an open access article distributed in accordance with the Creative Commons Attribution Non Commercial (CC BY-NC 4.0) license, which permits others to distribute, remix, adapt, build upon this work non-commercially, and license their derivative works on different terms, provided the original work is properly cited, appropriate credit is given, any changes made indicated, and the use is non-commercial. See: http://creativecommons.org/licenses/by-nc/4.0/.

ORCID iD

Koji Kitazawa http://orcid.org/0000-0003-2203-5776

\section{REFERENCES}

1 Melles GR, Eggink FA, Lander F, et al. A surgical technique for posterior lamellar keratoplasty. Cornea 1998;17:618-26.

2 Terry MA, Ousley PJ. Deep lamellar endothelial keratoplasty in the first United States patients: early clinical results. Cornea 2001:20:239-43.

3 Price FW, Price MO. Descemet's stripping with endothelial keratoplasty in 50 eyes: a refractive neutral corneal transplant. $J$ Refract Surg 2005;21:339-45.

4 Price MO, Price FW. Descemet's stripping with endothelial keratoplasty: comparative outcomes with microkeratomedissected and manually dissected donor tissue. Ophthalmology 2006;113:1936-42.

5 Gorovoy MS. Descemet-stripping automated endothelial keratoplasty. Cornea 2006;25:886-9.

6 Lee WB, Jacobs DS, Musch DC, et al. Descemet's stripping endothelial keratoplasty: safety and outcomes: a report by the American Academy of ophthalmology. Ophthalmology 2009;116:1818-30.

7 Anshu A, Price MO, Tan DTH, et al. Endothelial keratoplasty: a revolution in evolution. Surv Ophthalmol 2012;57:236-52.

8 Melles GRJ. Posterior lamellar keratoplasty: DLEK to DSEK to DMEK. Cornea 2006;25:879-81.

9 Terry MA, Hoar KL, Wall J, et al. Histology of dislocations in endothelial keratoplasty (DSEK and DLEK): a laboratory-based, surgical solution to dislocation in 100 consecutive DSEK cases. Cornea 2006;25:926-32.

10 Eye Bank Association of America. Eye banking statistical report, 2015. Available: http://restoresight.org/wp-content/uploads/2016/ 03/2015-Statistical-Report.pdf [Accessed 3 Mar 2018].
11 Price MO, Gorovoy M, Price FW, et al. Descemet's stripping automated endothelial keratoplasty: three-year graft and endothelial cell survival compared with penetrating keratoplasty. Ophthalmology 2013;120:246-51.

12 Price MO, Calhoun P, Kollman C, et al. Descemet stripping endothelial keratoplasty: ten-year endothelial cell loss compared with penetrating keratoplasty. Ophthalmology 2016;123:1421-7.

13 Ang M, Soh Y, Htoon HM, et al. Five-year graft survival comparing Descemet stripping automated endothelial keratoplasty and penetrating keratoplasty. Ophthalmology 2016;123:1646-52.

14 Nishino T, Kobayashi A, Yokogawa $\mathrm{H}$, et al. A 10-year review of underlying diseases for endothelial keratoplasty (DSAEK/ DMEK) in a tertiary referral hospital in Japan. Clin Ophthalmol 2018;12:1359-65.

15 Kitazawa K, Kayukawa K, Wakimasu K, et al. Predictive clinical factors of cystoid macular edema in patients with Descemet's stripping automated endothelial keratoplasty. Sci Rep 2017;7:7412.

16 Kitazawa K, Kayukawa K, Wakimasu K, et al. Cystoid macular edema after Descemet's stripping automated endothelial keratoplasty. Ophthalmology 2017;124:572-3.

17 Price MO, Fairchild KM, Price DA, et al. Descemet's stripping endothelial keratoplasty five-year graft survival and endothelial cell loss. Ophthalmology 2011;118:725-9.

18 Ratanasit A, Gorovoy MS. Long-term results of Descemet stripping automated endothelial keratoplasty. Cornea 2011;30:1414-8.

19 Wacker K, Baratz KH, Maguire LJ, et al. Descemet stripping endothelial keratoplasty for Fuchs' endothelial corneal dystrophy: five-year results of a prospective study. Ophthalmology 2016;123:154-60.

20 Nahum Y, Leon P, Mimouni M, et al. Factors associated with graft detachment after primary Descemet stripping automated endothelial keratoplasty. Cornea 2017;36:1-8.

21 Goshe JM, Terry MA, Li JY, et al. Graft dislocation and hypotony after Descemet's stripping automated endothelial keratoplasty in patients with previous glaucoma surgery. Ophthalmology 2012;119:1130-3.

22 Decroos FC, Delmonte DW, Chow JH, et al. Increased rates of Descemet's stripping automated endothelial keratoplasty (DSAEK) graft failure and dislocation in glaucomatous eyes with aqueous shunts. J Ophthalmic Vis Res 2012;7:203-13.

$23 \mathrm{Kim} \mathrm{P,} \mathrm{Amiran} \mathrm{MD,} \mathrm{Lichtinger} \mathrm{A,} \mathrm{et} \mathrm{al.} \mathrm{Outcomes} \mathrm{of} \mathrm{Descemet}$ stripping automated endothelial keratoplasty in patients with previous glaucoma drainage device insertion. Cornea 2012;31:172-5.

24 Anshu A, Price MO, Price FW. Descemet's stripping endothelial keratoplasty: long-term graft survival and risk factors for failure in eyes with preexisting glaucoma. Ophthalmology 2012;119:1982-7.

25 Aldave AJ, Chen JL, Zaman AS, et al. Outcomes after DSEK in 101 eyes with previous trabeculectomy and tube shunt implantation. Cornea 2014;33:223-9.

26 Anshu A, Price MO, Richardson MR, et al. Alterations in the aqueous humor proteome in patients with a glaucoma shunt device. Mol Vis 2011;17:1891-900.

27 Rosenfeld C, Price MO, Lai X, et al. Distinctive and pervasive alterations in aqueous humor protein composition following different types of glaucoma surgery. Mol Vis 2015;21:911-8.

28 Yazu H, Yamaguchi T, Dogru M, et al. Decreased visual acuity by an irregular corneal posterior surface after repeat Descemet stripping automated endothelial keratoplasty. Eye Contact Lens 2018;44 Suppl 1:S249-54.

29 Nahum Y, Mimouni M, Madi S, et al. Visual outcomes of repeat versus primary Descemet stripping automated endothelial Keratoplasty-A paired comparison. Cornea 2016;35:592-5.

30 Kitazawa K, Wakimasu K, Kayukawa K, et al. Moderately longterm safety and efficacy of repeat penetrating keratoplasty. Cornea 2018;37:1255-9.

31 Shimazaki J, Amano S, Uno T, et al. National survey on bullous keratopathy in Japan. Cornea 2007;26:274-8. 